
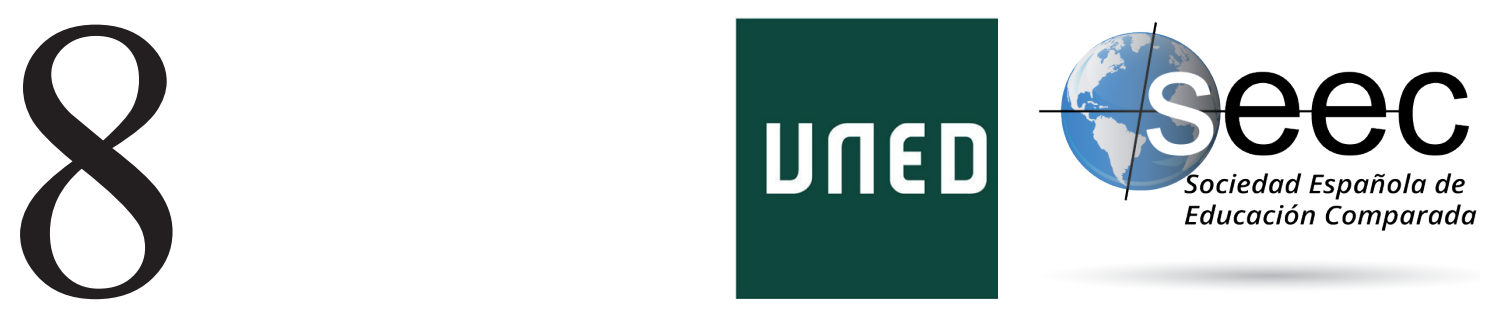

\title{
Educar el pasado: perspectivas para una investigación comparada sobre la «Historia profunda» $y$ «universal»
}

Educating to the past: perspectives for comparative research on 'deep' and 'universal' History

\section{David Salomoni*}

DOI: $10.5944 /$ reec.34.2019.24244

\author{
Recibido: 16 de abril de 2019 \\ Aceptado: 27 de junio de 2019
}

\footnotetext{
* DAVID SALOMONI: Profesor de la Università degli studi Roma Tre, del Dipartimento di scienze dell' educazione. Entre sus reputados trabajos destacan obras como: Salomoni, D. y Madella, L. (2018) Ensayo de una bibliografía comparada sobre la Universidad y el sistema de enseñanza superior (1990-2017), en P. Aullón de Haro (Coord.), La cuestión Universitaria, Metodologías Humanísticas, 1, Madrid, Instituto Juan Andrés; (2016) Le scuole di una comunitá emiliana nel Rinascimento tra religione e politica. Il caso di Novellara, Educazione. Giornale di pedagogia critica, 2. Datos de contacto: E-mail: salomoni@uniroma3.it
} 


\title{
Resumen
}

En el presente artículo se ilustra la tendencia reciente que caracteriza la historiografía contemporánea: el retorno a una concepción universal de la historia. El universalismo se traduce principalmente en una visión global y "profunda» del pasado. Este enfoque se valora aquí mediante la observación comparativa de algunos trabajos recientes que han provocado un animado debate en la comunidad académica. Cabe recordar que este enfoque no es nuevo, sino que se trata más bien de un retorno. Las obras históricas más importantes compiladas desde la Edad Media hasta el nacimiento de la Edad Moderna han considerado la historia en su conjunto. La reducción de los arcos temporales analizados, aunque respondiera a necesidades contingentes, provocó cortocircuitos culturales que impidieron captar los desarrollos históricos estudiados. En este artículo, trataré de poner en diálogo el antiguo universalismo con el universalismo moderno, subrayando el valor pedagógico de esta forma de escribir la historia y la centralidad de las instituciones educativas en su consolidación y transmisión. Las obras historiográficas aquí consideradas no agotan necesariamente todo el panorama de las publicaciones sobre este tema. Sin embargo, en mi opinión, son las más representativas e innovadoras de esta nueva y, al mismo tiempo, antigua tendencia. Lo que tienen en común es la renovada sensibilidad de la comunidad científica hacia un enfoque multidisciplinario e inclusivo, que utiliza las recientes adquisiciones de una amplia gama de ciencias, entre ellas la geología, la antropología, la arqueología y la física, para el estudio de la historia humana.

Palabras clave: Educación; Universalismo; Historiografía; Historia Profunda; Historia Global

\begin{abstract}
This article takes into account the recent trend of historiography towards a return to a universal conception of history. This universalism consists mainly in a global and profound vision of the past. Such an approach is assessed here through the comparative observation of some recent works that have provoked a lively debate in the academic community. This orientation, however, is far from new; it is rather a return. The most important historical works produced from the Middle Ages to the eve of modernity, in fact, have considered human history as a whole. The reduction of the time frames in scholarly works analysed here, although responding to contingent and concrete needs, according to some intellectuals caused cultural 'short circuits' that prevented us from grasping the same historical events that historians were trying to understand and guide. In this article, I will try to put ancient universalism into dialogue with modern universalism, underlining the pedagogical value of this way of writing history and the centrality of educational institutions in consolidating and transmitting it. The historiographical works considered here do not necessarily exhaust the whole panorama of publications on this theme. In my opinion, however, they are the most representative and innovative of this new and at the same time ancient trend. What they have in common is the renewed sensitivity of the scientific community towards a multidisciplinary and inclusive approach, which uses the recent acquisitions of a wide range of sciences, including geology, anthropology, archaeology, physics, for the study of human history.
\end{abstract}

Key Words: Supranational Education Policy; European Union; Axiological Framework; Interests; Principles; Values 


\section{Nota introductoria}

Los últimos veinte años de la historia mundial han sido el escenario de la violenta e inesperada ruptura de los equilibrios internacionales (económicos y políticos), así como de las certezas y esperanzas que animaron la planificación política y el crecimiento económico mundial en la segunda mitad de los años noventa. Una vez que el «fin de la historia», profetizado tras el colapso del bloque soviético, había sido archivado, vimos la entrada en un nuevo orden mundial en el que el radicalismo religioso, en contra de todas las expectativas del siglo XX, sustituyó parcialmente a las ideologías del «siglo corto» al dar voz a las reivindicaciones de grandes segmentos de las sociedades europeas y de Oriente Medio (Hobsbawm, 1994). Además, a principios de la década del 2000 se demostró que la «victoria» del bloque occidental sobre el comunismo no sancionaba la afirmación del modelo democrático como régimen político dominante, a pesar de los intentos de exportación del mismo. En varios estados del mundo, incluyendo los estados occidentales con una tradición democrática más antigua, la tentación de sistemas autoritarios de gobierno ha sido fuerte, consolidando en varios casos la posición de «hombres fuertes» al mando. La crisis económica que comenzó en 2008 hizo el resto, acelerando un proceso de desconfianza generalizada. Frente a estos cambios repentinos, el entorno de quienes estudian el pasado profesionalmente, a los que la opinión pública encargó la tarea de plantear las interpretaciones del presente, no ha dejado de preguntarse ¿qué salió mal? ¿por qué?

Una respuesta a tales preguntas provino de la historiografía anglosajona, tal vez porque el liderazgo mundial en el último siglo fue sucesivamente inglés y norteamericano. Los historiadores anglosajones han elaborado así algunas propuestas sobre el nivel de contenido y el método para tratar de comprender lo que ha sucedido, quizás refiriéndose a la categoría histórica más antigua pero parcialmente abandonada, la de universalismo, que ahora se define más comúnmente como global history e historia «profunda» (deep history). Algunos estudiosos, de hecho, se han dado cuenta de que en la investigación histórica la tendencia a lo largo del tiempo se ha orientado cada vez más hacia la fragmentación de los marcos temporales y de los objetos estudiados con un enfoque micro histórico. El problema, según algunos, no radica tanto en el enfoque micro histórico en sí mismo, capaz de alcanzar niveles de análisis muy precisos, sino en la propensión a un uso desproporcionado de este método como única herramienta de análisis histórico destinada a imprimir un cambio en la sociedad, abandonando pues las lecciones de las escuelas historiográficas del pasado.

Este artículo no pretende agotar el tema del retorno contemporáneo a un enfoque histórico universalista, ni pretende una comparación exhaustiva de todas las obras históricas universalistas pasadas y presentes, sino ofrecer consideraciones e interpretaciones a fin de comprender mejor y orientarse en la fase historiográfica presente. Por lo tanto, aquí compararemos algunos trabajos recientes de historiadores en los que se ha expresado la necesidad de volver a un enfoque holístico de la historia en un sentido horizontal: el mundo (historia global); y vertical: el tiempo (historia profunda). El contenido de estas obras también se comparará con otras del pasado, subrayando que el enfoque universal (global y profundo) es solo un retorno a una forma bien establecida de hacer historia. Como veremos enseguida, la reducción de los plazos estudiados es un fenómeno relativamente reciente en la historiografía. 


\section{2. "Deep History" y "Short Termism"}

En un libro publicado hace unos años, los historiadores David Armitage y Jo Guldi advirtieron contra el riesgo de una historiografía aplastada sobre lo contemporáneo o sobre la corta, incluso muy corta, duración (Armitage-Guldi, 2014: 1-3). El History Manifesto, de hecho, indicaba que una de las principales causas de la crisis política, económica y antropológica experimentada en los países occidentales durante los últimos años era la reducción progresiva del horizonte cronológico en el campo de la investigación histórica. En opinión de los dos historiadores, a lo largo de la segunda mitad del siglo XX, la afirmación gradual de una atención de los estudiosos cada vez más concentrada en los fenómenos de corto plazo (short-termism), en detrimento de una perspectiva más amplia, de larga duración, estaría en la base de la crisis que las disciplinas históricas están experimentando en la sociedad contemporánea, al menos en la sociedad occidental (Sisci, 2013).

Según estos historiadores, la falta de una visión de conjunto socavaría la capacidad colectiva de elaborar visiones a largo plazo, propiciando la devaluación colectiva de la reflexión histórica y su tradicional utilidad: magistra vitae. De hecho, mirando el debate público en algunos países, como Italia, en los últimos años se ha confirmado la idea de la inutilidad de las disciplinas liberales tradicionales, con la historia a la cabeza. Varios periodistas, intelectuales y líderes de opinión han trabajado conjuntamente para demostrar cuánto en la civilización del Homo Oeconomicus, las disciplinas resultantes de los esfuerzos de producción e identidad nacional y análisis social del siglo XIX se han convertido ahora en un mero adorno para el intelecto, con poco que aportar a la expansión económica de un estado (Feltri, 2016).

Es interesante notar que ambas posiciones, tanto la de los devaluadores de la importancia del papel público de la historia en el mundo contemporáneo, como la de aquellos que identifican en la investigación histórica a largo plazo una perspectiva metodológica capaz de sacar a esta disciplina del estado de subalternidad política y académica en el que habría caído, reconocen la esfera educativa como momento crucial. Para los detractores, de hecho, serían las bajas tasas de empleo de los licenciados en literatura/historia las que sancionarían su falibilidad, mientras que los partidarios del retorno a la función programática con un enfoque de longue durée parten de las instituciones educativas y de la actividad de investigación académica para determinar la necesidad de esta revolución, en el sentido etimológico del término. Guldi y Armitage afirman que entre 1975 y 2005, las tesis doctorales producidas en Estados Unidos trataron principalmente temas con una duración cronológica entre 5 y 25 años, mientras que en 1900 la media de los plazos examinados en las tesis doctorales era de 75 años (Armitage-Guldi, 2014, p. 7-8). Este libro, tras el debate académico al que dio lugar, tiene el mérito de haber puesto de relieve dos aspectos importantes de la sociedad contemporánea.

El primero es la importancia de las instituciones educativas, en particular las universidades, para determinar la orientación (y el enfoque) de las representaciones del pasado, a fin de influir en la percepción colectiva del presente en los diversos ámbitos de la sociedad, desde la política hasta la economía. El segundo elemento está más estrechamente relacionado con el campo historiográfico, en particular con la manera en que las distintas épocas han mirado al pasado, seleccionando temas, problemas y segmentos más o menos amplios. El debate sobre el mejor enfoque del análisis del pasado, holístico o parcial, es probablemente el problema historiográfico más antiguo, anterior al nacimiento de la historia como disciplina autónoma y científica. 
El History Manifesto, sin embargo, no es solo un llamamiento a la comunidad científica para que vuelva a un enfoque de larga duración, sino que es también el producto de una determinada visión historiográfica que desde hace tiempo ha sentido la necesidad de recuperar una visión más amplia del pasado. De hecho, la reducción del arco temporal del análisis histórico destacada por Guldi y Armitage es solo la punta del iceberg cuyos orígenes se pueden rastrear muy atrás en el tiempo. Los historiadores no han dejado de cuestionar la razón de esta reducción.

En un libro publicado en 2008, On Deep History and the Brain, Daniel Lord Smail afirmaba con fuerza la necesidad de una reunificación de la historia, una aproximación al pasado capaz de abandonar los prejuicios todavía arraigados entre los historiadores contra lo que se define como «prehistoria», es decir, todo lo que precede a «esa abstracta «raza humana» que se encuentra en la historiografía humanista» (Smail, 2008, p. 2; Greene, 1992, p. 3). Según Smail, la forma en que los historiadores miran el pasado ha sido influido por teorías «fantasma», de las cuales hablaré brevemente, pues han estructurado su forma de pensar de manera no plenamente consciente.

Sin embargo, los avances logrados hoy en día por otras disciplinas, como la antropología, la arqueología, la biología, la neurociencia, la psicología, pueden emplearse para reescribir radicalmente la imagen de un Paleolítico inmutable. En este sentido, la línea ya había sido trazada hace algún tiempo. Este enfoque fuertemente interdisciplinario es solo la etapa más avanzada de aquello que la escuela de los Annales franceses comenzó en la primera mitad del siglo XX, y que luego se tradujo en las diversas vías de investigación histórica renovada, vigentes cincuenta años más tarde en el libro editado por Jacques Le Goff y Pierre Nora, titulado Faire de l'histoire (Le GoffNora, 1974). Algunos de los temas de renovación historiográfica indicados en el libro fueron instrumentales en el estudio del pasado profundo y podemos encontrarlos en otro libro posterior de Smail escrito con Andrew Shryock. Entre los puntos tratados se encuentran la historia del cuerpo, el lenguaje, la energía, la alimentación, la migración y el parentesco (Shryock-Smail, 2011). Incluso la escuela de los Annales no ha dejado de interesarse por el problema de la unidad histórica, la continuidad entre épocas y las razones que obligan a los historiadores a operar periodizaciones. Jacques Le Goff publicó en 2014, año de su muerte, el libro Faut-il vraiment découper l>histoire en tranches? en el cual el historiador francés discute estos asuntos (Le Goff, 2014).

En síntesis, la idea de estas reflexiones es escribir una historia unitaria del hombre, desde el Paleolítico hasta el post-Lítico, sin que lo que ocurrió antes de las formas más antiguas de testimonio escrito sea concebido como una forma de antropología en clave histórica, sino como una historiografía completa. Todo ello sin abandonar el valor de la reflexión sobre los periodos, que es siempre una herramienta fundamental, pero sin impedir que las periodizaciones se conviertan en cotos sagrados e insuperables.

Según Smail, tratar el pasado del hombre de manera unificada sería fundamental con el fin de alcanzar una mejor comprensión y una mayor conciencia de la acción humana en el presente. De esta manera, Smail conecta con las posiciones de Armitage y Guldi, compartiendo su atractivo. Incluso para el autor de Deep History, la tendencia resalta una reducción de los arcos cronológicos examinados por los historiadores. Señala que durante siglos los historiadores han producido y enmarcado sus representaciones del pasado desde los orígenes de la humanidad hasta sus respectivas épocas contemporáneas sin que, sin embargo, estas historias se consideren profundas debido a la «corta» duración de la historia bíblica en la tradición judeo-cristiana. En el relato bíblico, en efecto, el 
hombre es creado ya en posesión de todas sus facultades racionales, sin pasar por esa fase de amortiguación que hoy entendemos como prehistoria. Es innegable, sin embargo, que el habitus mental con el cual se escribieron estas historias fue exquisitamente holístico, es decir, pretendía dar cuenta de todo el conocimiento existente y compartido sobre la historia humana. ¿Qué es lo que ha cambiado la actitud de los historiadores (incluso ante litteram), provocando la reducción gradual de los arcos cronológicos investigados?

\section{Entre ciencias de la Tierra e historia sacra}

Como señala Daniel Lord Smail, hay un rasgo común entre las historias universales producidas en la Antigüedad y la Edad Media, las historias globales de los siglos XIX y XX, e incluso los libros de texto de historia: todas afirman comenzar su tratamiento desde el principio. Sin embargo, el problema que plantea este enfoque es decidir cuándo colocar el comienzo de la historia de la humanidad. El problema no se planteó durante mucho tiempo. Los dos modelos de periodización de los historiadores tardoantiguos y medievales fueron el propuesto por Daniel en el Antiguo Testamento y el de San Agustín del IX libro de la Ciudad de Dios (Le Goff, 2014, p. 10-11). Al profeta Daniel cuatro bestias encarnando las cuatro edades del hombre se le manifiestan en un sueño. Éstas se devoran unas a otras hasta que la última blasfemia contra Dios, y en ese momento aparece el Hijo del Hombre, a quien son conferidos por el Cielo el Imperio, el Honor y el Reino. Como señala Le Goff, esta periodización prosperó entre los historiadores de los siglos XII al XVI. Los cuatro reinos aún dividen la historia universal de Felipe Melanchthon y todavía está vigente en 1557, en el De quatuor summis imperiis de Johannes Sleidanus (Le Goff, 2014, p. 11; Ben-Tov, 2009; Suggi, 1998, p. 75-92).

Por su parte Agustín divide la historia no en cuatro épocas sino en seis partes, las cuales se refieren a los seis días de la creación y a las seis edades de la vida (infancia, niñez, adolescencia, juventud, madurez y vejez). También la subdivisión de Agustín tuvo mucho éxito entre los historiadores de la Antigüedad tardía y de la Alta Edad Media, influyendo en sus obras. Entre ellas se encuentran las Etimologías de Isidoro de Sevilla (siglos VI-VII), la De temporum ratione de Bede el Venerable (siglos VII-VIII) y, en épocas posteriores, el Speculum historiale de Vicente de Beauvais (siglo XIII), (Le Goff, 2014, p. 15).

Los historiadores medievales no dudaron en colocar el origen de la historia en el Jardín del Edén, superponiendo perfectamente la historia sagrada a la historia profana. Guillaume de Nangis, uno de los intelectuales franceses más famosos de la Edad Media, contemporáneo de Vicente de Beauvais, en su Chronicon empieza la historia del hombre con la creación, llegando luego hasta su época (comienzos del siglo XIV), (BussacGermain, 2010, p. 5-6). A su vez, Guillaume de Nangis se basó en las obras de sus predecesores: es el caso del monje benedictino Sigebert de Gembloux, cuya Chronographia,

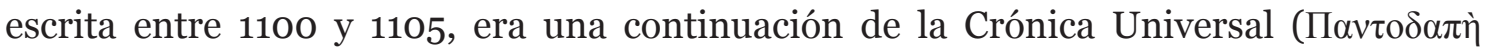

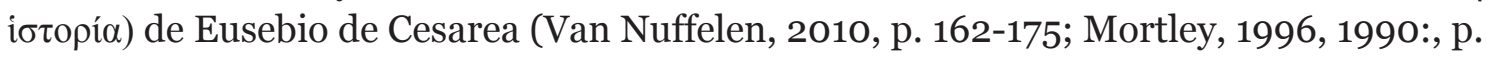
225-250). La Cronographia de Sigeberto, que comenzaba en 381 (año en el que termina la Crónica de Eusebio) es testimonio de la voluntad enciclopédica y universal del autor, así como de su necesidad de completar la obra.

Como hemos mencionado con anterioridad al hablar de la influencia del libro de Daniel sobre Melanchthon, el enfoque universalista de la historia continuó a lo largo de la era moderna. El propio Voltaire lo demuestra y, en su obra Le Siècle de Louis XIV escrita en 
1751, divide la historia del hombre en cuatro siglos: la antigua Grecia, la Roma imperial, el Renacimiento italiano y el siglo de Luis XIV «que más que nunca se acerca a la perfección» (Voltaire, 1994, p. 112). Así, el significado de «siglo» en Voltaire no coincide con el significado actual de «lapso temporal de cien años». La acepción del término empleado por el filósofo francés define el apogeo de una época de la humanidad (Le Goff, 2014, p. 18). Los intelectuales de la Ilustración continuaron incidiendo en la concepción universalista, profunda y global de la historia. Los ejemplos significativos en este sentido serían muchos. Entre ellos, cabe destacar el caso del jesuita español Lorenzo Hervás y Panduro, uno de los miembros más importantes de la Escuela Universalista Española junto con Juan Andrés y Antonio Eximeno, y figura clave en el proceso de fundación de la Lingüística comparada como disciplina de investigación autónoma (Aullón de Haro, 2016).

Tras la expulsión de los jesuitas del Reino borbónico, Hervás se exilió a Italia, estableciendo su residencia finalmente en la ciudad de Cesena, donde vivió durante 15 años, para luego trasladarse a Roma. En su exilio italiano Hervás pudo contactar con los diferentes misioneros filipinos y americanos expulsados de los territorios ultramarinos de la Corona española: sus correligionarios fueron informantes decisivos para la compilación del Catálogo de las lenguas. Además de esta importante obra de Lingüística comparada, escribió una Storia della Terra, publicada en 6 volúmenes entre 1781 y 1783, pero especialmente el tratado de cosmología Idea dell'Universo, publicado en Cesena entre 1778 y 1787 en 21 volúmenes (Hérvas, 1778-1787, 2011). La extrema modernidad de esta obra reside en la concepción totalmente unificada de Hervás de la historia y la prehistoria humana, obviamente dentro de los límites del conocimiento científico de la época. De hecho, Hervás considera todos los ámbitos de la historia humana, tanto orgánica como inorgánica, combinando geología, paleontología y cosmología en una interacción entre disciplinas que recuerda la de Daniel Smail citada al principio.

A partir del siglo XVIII, sin embargo, se dieron algunos cambios radicales en la forma de concebir el pasado. La aparición de una visión más racional y crítica de la realidad, consecuencia del pensamiento de la Ilustración, llevó el problema de la cognoscibilidad del «origen' al centro de la reflexión histórica. Giambattista Vico, por ejemplo, en la Scienza Nuova de 1725, afirmó que no se podía saber nada de la historia humana con antes del Diluvio Universal, acontecimiento que había borrado todo lo que existía antes (Vico, 1744). Comenzar la narración histórica a partir de este momento, por lo tanto, significaba afirmar un nuevo paradigma historiográfico, que tendría un enorme impacto en el desarrollo futuro de la disciplina. Se planteó una primera distinción entre historia sagrada y secular; pero sobre todo se fue desdibujando el concepto de una Edad de Oro y la consecuente supuesta decadencia y corrupción de la humanidad. Con el grado cero del Diluvio, en cambio, se afirmó una visión progresiva y progresista de la historia humana. Además, con el Diluvio, por primera vez, se diseñó un acercamiento a la historia en medias res, es decir, no desde el principio (real o supuesto), sino desde un momento determinado, decidido por razones de crítica histórica (Smail, 2008: 21). De esta manera, se inició la reducción de los arcos de tiempo estudiados y la compresión del tiempo histórico. Sin embargo, el tiempo histórico, en su conjunto, mantenía una breve duración. Si Vico empezó la historia en 1656 A. M. (Anno Mundi), Eusebio de Cesarea había fijado la creación de Adán en 5198 a.C.: a la luz de un cómputo global las cosas no cambiaron mucho.

Otros problemas comenzaron a surgir en la edad moderna a partir de la comparación con otras cronologías. La expansión de los estados europeos de ultramar puso en 
contacto las potencias del viejo continente con otras civilizaciones, cuyos métodos historiográficos no siempre confirmaban los elementos dados con seguridad en el cristianismo (Smail, 2008, p. 36-37). La cosmología china, por ejemplo, consideraba un lapso temporal de 880.000 años y, en 1658, el jesuita Martino Martini, comparando los anales chinos y europeos, observó algunos historiadores chinos registraban acontecimientos ocurridos 600 años antes del Diluvio (Rossi, 1984, p. 136-140). ¿Cómo era posible si esa catástrofe había borrado todo rastro de la actividad humana anterior? Otro desafío a la historia sagrada también vino del avance de nuevas disciplinas científicas: la geología, la paleontología, la historia natural. Los fósiles marinos encontrados en las cimas de las montañas, observa Smail, crearon muchos problemas de interpretación.

Sin entrar en la enunciación de las diversas teorías elaboradas para resolver estas cuestiones, bastará con observar cómo entre finales del siglo XVIII y finales del XIX se abrió paso en la comunidad científica una nueva concepción del tiempo que consideraba una duración de cientos de miles (e incluso millones) de años. Sin embargo, los historiadores no parecían prestar mucha atención a este nuevo planteamiento. Aunque la producción de historias universales no cesó, y de hecho continuó con cierta vitalidad tanto en Europa como en América, el interés historiográfico que dominó el siglo XIX se dirigió hacia la historia de las naciones individuales, en función de los procesos de construcción cultural y política de los estados. Es el momento en que la historia se convierte en una disciplina autónoma con un estatus científico pleno. Es la época en que, incluso en la universidad, la ciencia histórica se convierte en tema de enseñanza (Le Goff, 2014, p. 39; 1988; Hartog, 2013; Koselleck, 1975). Este interés llevó al descubrimiento de la Edad Media como «momento cero» en el desarrollo de las naciones europeas.

La operación realizada entonces por los historiadores, sin embargo, supuso un correlato a la recuperación del catastrofismo viquiano del Diluvio, ahora transpuesto a la invasión por parte de los «bárbaros» del Imperio Romano, de cuyas cenizas habrían brotado luego los actuales estados-nación. De esta manera, puede plantearse un paralelismo entre el fin de la Antigüedad y el Diluvio viquiano, y la edad antigua (mesopotámicaegipcia-griega-romana) y la edad de oro de la humanidad de Hesíodo o el Edén bíblico. Así se llevó a cabo una transposición de la historia sagrada a una historia verificable. De un solo golpe se resolvió el problema de la larga duración, eliminando al menos cien mil años de la historia humana, y relegando el Paleolítico -la historia no verificable- a una especie de Edad Media de la humanidad, una época de oscura inmovilidad. Vemos actuar, en este mecanismo, las «teorías fantasmas» de las que hemos hablado al principio del artículo (Smail, 2008, p. 58). Estas estructuras de pensamiento siguen actuando incluso bajo diferente forma. Es cierto que también hubo problemas concretos para la inserción del Paleolítico en el ámbito disciplinario de la historia: es el caso de la ausencia de documentos escritos. Pero incluso lo que puede parecer «obvio» fue el resultado de una epistemología histórica que se definía de manera cada vez más precisa y que situaba el documento escrito en el centro del proceso de conocimiento. Esta operación de situar en el centro la fuente escrita no se dio por sentado. En los manuales de historia elaborados a mediados del siglo XIX se indicaba que no se debía omitir ninguna fuente indirecta. Pero la separación de los campos disciplinarios científicos entonces en curso exigía una clara distinción de competencias que determinaba la pertenencia de los especialistas a los distintos campos: arqueología, antropología, historia.

$\mathrm{Al}$ hacer coincidir el comienzo de la historia con la aparición de la escritura, podemos ver que la historia «científica» $\mathrm{y}$ «verificable» coincide, desde un punto de vista 
cronológico, con la historia sagrada que se acaba de dejar atrás y que, de hecho, se superpone a ella. Si la creación de Adán había sido fechada por Eusebio de Cesarea 5198 años antes de Cristo, la Tabla de Dispilio, uno de los testimonios escritos más antiguos jamás encontrados, está fechada en el año 5260 a.C. (Hourmouziadis, 2002). El marco ha cambiado, pero no la sustancia. Lo que realmente se ha transformado con el «fin» de la historia sagrada es la reducción del tiempo relativo considerado por los historiadores. En el caso de las historias universales que comienzan con la creación era toda la historia del hombre lo que se consideraba. Con la historia «del documento», aunque el arco estudiado es siempre de unos 6/7000 años, solo una limitada porción de tiempo se considera objeto digno de análisis.

\section{Historia y acción social}

La historiografía del siglo XIX, centrada en el nacimiento de las naciones, tenía como objeto principal una historia política, escrita por razones políticas. Este enfoque fue uno de los principales motivos por los que se comenzó a reducir la duración cronológica de los períodos estudiados. Con la consolidación de los Estados-nación como modelo político dominante, y con la posterior difusión de las ideologías políticas/económicas como instrumentos (a veces utópicos) de mejora de las condiciones del hombre, la atención de los historiadores siguió estando políticamente comprometida y al servicio de una determinada facción política. Este compromiso político, sin embargo, se concentraba cada vez más en lo contingente: el fin último era la realización de un cambio social lo más rápido e incisivo posible.

Como han señalado Armitage y Guldi, a partir de la década de 1970 se produjo una verdadera revuelta de toda una generación de historiadores contra el enfoque de la larga duración (Armitage-Guldi, 2014, p. 96-97). Otro factor importante a fin de determinar este punto de inflexión hacia el «corto plazo» fue algo similar a lo que había ocurrido en el siglo XIX, cuando la historiografía iba definiendo un campo disciplinario propio. La especialización profesional de los historiadores continuó, esta vez impulsada por la saturación del mercado académico. Los jóvenes historiadores nacidos durante el babyboom posterior a la Segunda Guerra Mundial, para conseguir un lugar en la Academia, tuvieron que afinar sus habilidades y determinar objetos de investigación cada vez más específicos. Un fuerte impulso para este cambio fue el deseo de tener un impacto real en el cambio social. Mediante el análisis de cuestiones raciales, de género o de clase en contextos geográficos y cronológicos restringidos, se esperaba comprender los microcambios reales de las relaciones interpersonales y laborales. La comprensión de estas dinámicas debía conducir pues al dominio y posible manipulación de las mismas. Un caso: las luchas de clases dentro de las ciudades o comunidades individuales, a veces referidas a un episodio particular, fueron muy estudiadas (Armitage-Guldi, 2014, p. 85; Roediger, 1991).

En la forma de escribir la historia que se afirmó en estos años, la tarea de elaborar los marcos generales fue dejada a los filósofos sociales franceses y alemanes, como Michel Foucault y Jürgen Habermas (Armitage-Guldi, 2014, p. 97-98; Foucault, 1975; Habermas, 1977). Este método no entró en conflicto con el deseo de los jóvenes historiadores de participar en los cambios políticos y sociales de su tiempo, sino que lo fortaleció. Estos intelectuales se convirtieron en los responsables de la tarea de definición de los contextos dentro de los que actuaban los historiadores. 


\section{El retorno a la larga duración y la importancia del principio educativo}

Cabe recordar que fue sobre todo en la forma de enseñar la historia donde se produjo un cambio decisivo. Paralelamente a la progresiva reducción de los arcos temporales estudiados a partir de los años 70, en las universidades se empezó también a enseñar a los estudiantes de historia que concentrasen sus esfuerzos de análisis en períodos de tiempo cada vez más breves. Armitage y Guldi recuerdan el conocido ejemplo citado en el manual para aspirantes a historiadores de la Escuela Americana de Florence McCoy de 1974, en el que se menciona el intento de una estudiante de elegir un tema de investigación. La estudiante, en el ejemplo mencionado, pasa de la idea de estudiar la figura de Oliver Cromwell, considerada por el manual demasiado vasta y por tanto no susceptible de un conocimiento específico, a la idea de estudiar la relación entre Cromwell y el problema de la unificación entre Escocia e Inglaterra, un tema capaz de aportar un conocimiento específico convirtiendo a la estudiante en cuestión en una experta en las relaciones diplomáticas anglo-escocesas (Armitage-Guldi, 2014, p. 98-99; McCoy, 1974: 3-6). Hasta entonces las propias universidades habían defendido, en cierta medida, la larga duración del enfoque de análisis de las nuevas generaciones de historiadores. En general, un trabajo que tomaba en cuenta un período de menos de 50 años era considerado negativamente, como irrelevante para una evaluación histórica profunda. A partir de 1979, sin embargo, el estigma de la brevedad disminuyó gradualmente, en la estela de los antecitados cambios sociales entonces en desarrollo.

A partir de ese momento, los jóvenes historiadores e investigadores se preocuparon cada vez menos por contextualizar sus trabajos, centrándose en horizontes temporales cada vez más acotados. Con el paso del tiempo sus obras se hicieron menos comprensibles para el público en general, debido a la falta de referencias contextuales útiles a fin de enmarcar los fenómenos considerados; se dio, por ende, una verdadera división entre el mundo académico-educativo y la sociedad (Armitage-Guldi, 2014, p. 101; Rodgers, 2011: 55). En cierto sentido, fue precisamente este cortocircuito el que redujo gradualmente la capacidad colectiva para elaborar visiones políticas, económicas y éticas a medio y largo plazo. Hasta hace algunas décadas, la sociedad civil compartía el interés por la investigación histórica informándose acerca de las más recientes adquisiciones de la historiografía a través de la lectura de revistas especializadas.

Este interés tenía el efecto de estructurar la forma de pensar de la sociedad, aportando elementos críticos básicos con los que se podía elaborar un esquema interpretativo de la realidad en la que se vivía y se trabajaba. Desde este punto de vista, el anclaje de los fundamentos de cada disciplina en la tradición clásica, planteamiento que duró al menos hasta los años 60, desempeñó un papel no secundario en la orientación de los intereses y acciones intelectuales de los individuos. Sin embargo, el alejamiento gradual de los historiadores del contexto general en el que se situaba su investigación siguió erosionando el surco que separa a la sociedad de la investigación universitaria. Frente al colapso de las estructuras ideológicas que guiaban las acciones de los historiadores y les permitían dejar en segundo plano el problema de la larga duración, nada intervenía para compensar ese vacío. Desde comienzos de los años 90 se ha establecido una tecnocracia 
pura, carente de cualquier implicación utópica, ética o ideal capaz de guiar el progreso material y tecnológico.

El problema es que permaneció en la conciencia colectiva la misma convicción de vivir en la mejor de las épocas posibles propia de los intelectuales ilustrados del siglo XVIII, pero sin poseer ya las herramientas críticas para comprender el curso de los acontecimientos y dirigir la acción hacia un fin. Estas herramientas críticas fueron proporcionadas precisamente por una concepción de la historia de larga duración, o «profunda», como diríamos hoy. En estos términos, es la acción educativa la que debe facilitar una vuelta a la concepción contextualizadora y "profunda» de la historia. Bien es cierto que el mundo de la educación ya ha dado algunos pasos importantes (Romio, 2018). Una interacción entre conocimientos y habilidades deseada por Smail, pero ya implementada hace siglos por Lorenzo Hérvas, es posible. Para ello es esencial el compromiso de las instituciones educativas de todos los niveles, desde la enseñanza secundaria hasta las universidades. En el ámbito de la enseñanza superior y universitaria, de hecho, se está produciendo un cambio de tendencia. De hecho, los autores mencionados hasta ahora -Armitage, Smail, Guldi, Le Goff, Nora- son todos académicos.

Otro aspecto es el impulso dado por las nuevas generaciones de historiadores hacia la historia universal. Aunque todas o casi todas las obras mencionadas hasta ahora son el resultado de profesores y personalidades de la vieja escuela universitaria, no faltan jóvenes historiadores que adoptan el enfoque universalista. Es el caso, por ejemplo, del israelí Yuval Noha Harari, actualmente profesor de Historia Mundial y Procesos Macrohistóricos en la Universidad Hebrea de Jerusalén. Sus obras más representativas son Sapiens: A Brief History of Humankind, publicada en 2014, Homo Deus: A Brief History of Tomorrow, publicada en 2015, y 21 Lessons for the 21st Century, publicada en 2018 (Harari, 2018, 2016, 2014). Los tres libros están idealmente concebidos como una trilogía. En estos libros, el autor traza la historia de la humanidad en el contexto de un análisis en el que las principales claves interpretativas son las ciencias naturales y la biología evolutiva.

La historia del hombre se considera, por tanto, como un todo, sin distinguir entre la edad pre y post lítica, retomando así el llamamiento lanzado por Daniel Smail unos años atrás. Harari establece los límites biológicos del hombre como fronteras de su acción en el mundo, pero es interesante notar que, incluso tras la innovación aportada por las nuevas disciplinas científicas al estudio de la historia humana, la subdivisión de las macro-edades histórica de Harari es sorprendentemente similar a la antigua división en 4 períodos, comenzada con el libro bíblico de Daniel y continuada hasta el umbral del mundo contemporáneo. Harari divide así la historia en:

1) la Edad de la revolución cognitiva, cuando los sapiens desarrollaron formas de imaginación y abstracción (70.000 a.C.-10.000 a.C.);

2) la Edad de la Revolución agrícola, que dio lugar a la formación gradual de sociedades políticas sedentarias y jerárquicas (10.000 a.C.-3)..ooo a.C.);

3) la Edad de la unificación de la raza humana, en la que las estructuras políticas y los imperios creados por el hombre se hicieron cada vez más amplios, estructurados y homogéneos, desencadenando un proceso de globalización y homogeneización de la humanidad (3.000 a.C.-1.500 d.C.);

4) la Edad de la Revolución científica, en la que, gracias a sus habilidades técnicas, los hombres pudieron llegar a ser cada vez más arquitectos de su propio destino. 
La cuadripartición de la obra de Harari revela una estructura muy similar a la del libro de Daniel, demostrando que el enfoque y las formas de reflexión sobre el pasado universal no han cambiado mucho respecto a las estructuras cognitivas antiguas, medievales y modernas. Otro trabajo reciente e importante sobre el pasado profundo y global viene siempre del mundo universitario. El título es Against the Grain, y aunque su autor, James Scott, no es tan joven como Harari, el enfoque es innovador (Scott, 2017). El autor, de hecho, invierte por completo la perspectiva y el juicio sobre uno de los supuestos más sólidos y estructurados de nuestra forma de enseñar y concebir el pasado de la humanidad: el papel de la Revolución agrícola, elemento central también para Harari, en la configuración del mundo moderno.

Es comúnmente sabido que el desarrollo y la difusión de la práctica agrícola que comenzó en los humedales de Oriente Medio, particularmente en la fértil Media luna y a lo largo del curso del Nilo, ha hecho posible en última instancia el desarrollo de la civilización tal como la conocemos ahora, permitiendo la acumulación de alimentos suficientes para sustentar los principales desarrollos demográficos, el nacimiento de ciudades, sociedades políticas y, más tarde, imperios «civilizadores». La difusión de la agricultura representa precisamente uno de los puntos de inflexión en la transición de la «prehistoria» a la «historia», y el hecho de que ello haya desempeñado un papel decisivo para el destino del ser humano está fuera de toda duda. Según Scott, sin embargo, las consecuencias negativas de este cambio serían superiores a las positivas. Las nuevas agregaciones sociales, causa y efecto de la Revolución agrícola, habrían conducido a:

1) una fuerte jerarquía social, a partir de las formas de esclavitud que han perdurado hasta el mundo contemporáneo;

2) el desarrollo del concepto de propiedad privada;

3) el nacimiento del racismo cultural, en relación con el descrédito hacia las formas de vida nómadas alimentado por las sociedades sedentarias;

4) el aumento de la mortalidad causada por las epidemias consecuencias de las nuevas grandes agregaciones de individuos.

Para llegar a estas conclusiones, Scott trabajó con fuentes pertenecientes tanto a la mitología como a la antropología. En la mitología griega, por ejemplo, la agricultura se describe positivamente como un regalo de los dioses (Atenea dona el olivo a Atenas), y no es casualidad que la civilización helénica tuviera una visión negativa de otras culturas y una fuerte vocación imperialista desde sus comienzos. En la civilización judía, en cambio, el eco del dolor del paso de una forma de vida nómada y recolectora, simbolizada por el jardín del Edén, a una forma de sociedad agrícola permanente, representada por la expulsión del Jardín, siguió siendo fuerte. En efecto, en el Génesis Dios dijo al hombre: «iMaldita será la tierra por tu causa! Con trabajo sacarás de ella el alimento todos los días de tu vida; espinas y cardos te producirá, y la hierba del campo comerás. Con el sudor de tu rostro comerás el pan, hasta que vuelvas a la tierra» (Génesis, 3, 17-19). En estas palabras, persiste viva la memoria colectiva del paso del nomadismo al sedentarismo.

No es de extrañar que estos trabajos de investigación sobre la historia profunda, resultado de una renovada sensibilidad del mundo académico y educativo, recibieran la crítica más feroz del mundo del periodismo y la economía. En estas áreas, de hecho, la atención se centra cada vez más en el acontecimiento inmediato, el momento presente, la repercusión emocional que los hechos tienen sobre el rendimiento de las bolsas. En otras palabras, una visión humanista y compleja de la realidad no es «rentable», al 
menos en la inmediatez, y no vale el tiempo de la reflexión. Sin embargo, como dijo Craig Calhoun, ex director del American Social Science Research Council y de la London School of Economics, "Public engagement was a strong feature of the social sciences from their birth" (Armitage-Guldi, 2014, p. 124; Calhoun, 2008, p.299-318). Es de esperar, por tanto, que el llamamiento del mundo de las universidades y de las escuelas para un estudio universal y "profundo» de la historia sea asumido por los educadores de todos los niveles, a fin de que la gente se acostumbre a un razonamiento contextualizado y crítico, sin el cual los desafíos del mundo presente y del futuro no pueden ser afrontados y comprendidos.

\section{Conclusión}

En este artículo se han comentado algunos de los principales trabajos relativos a los desarrollos más recientes del enfoque historiográfico universalista, al mismo tiempo nuevo y antiguo. Hemos visto cómo la concepción unificada de la historia humana puede considerarse un hilo que une todas las producciones históricas e historiográficas del pasado, incluso antes del nacimiento de la historiografía como disciplina autónoma. Desde la Antigüedad hasta la Edad Media se han trazado los grandes modelos conceptuales y estilísticos de esta forma de hacer historia, desde Eusebio de Cesarea hasta San Agustín, desde Isidoro de Sevilla hasta Beda el Venerable, pasando por Sigebert de Gembloux y Vicent de Beauvais. Incluso la Edad Moderna temprana ha aceptado estas estructuras historiográficas con relativa convicción. Prueba de ello son, por ejemplo, las obras de Felipe Melanchthon y Voltaire. Sin embargo, fue entre el final de la primera época de la modernidad y el comienzo de la era contemporánea cuando el enfoque «profundo' y holístico de la producción historiográfica alcanzó su punto más alto. Precursor de una visión de historia profunda más racional y menos influenciada por modelos bíblicos fue Giambattista Vico, en su Scienza Nuova (1725). Sin embargo, fueron los intelectuales de la Escuela Universalista Española, los jesuitas Juan Andrés y especialmente Lorenzo Hervás, quienes elaboraron esta metodología de una manera más precisa. De hecho, Hervás considera todas las áreas de la historia humana, tanto orgánicas como inorgánicas, combinando la geología, la paleontología, la cosmología y la antropología de un modo que, por supuesto, está en consonancia con el conocimiento de su tiempo sobre estas disciplinas.

A pesar de ello, la propia afirmación de la historia como ciencia independiente ha llevado a una inflexión en lo que concierne el período de tiempo considerado por los historiadores. Al desarrollo de este fenómeno ha contribuido el compromiso social y político que la historiografía asumió a partir del siglo XIX, alcanzando su punto álgido en los años 60 y 70 del siglo XX. La reducción de los períodos considerados ha provocado una disminución de la capacidad de los historiadores para comprender la dinámica de su propio presente, debido a la creciente dificultad de contextualizar los acontecimientos en un contexto más amplio. Esto ha llevado a una suerte de descrédito generalizado de las disciplinas históricas, situación de las que se ha intentado salir solo recientemente. El mundo de las universidades y las escuelas, de hecho, ha asumido el reto y una serie de nuevas publicaciones han comenzado a ver la luz, recuperando vigorosamente una perspectiva unitaria y universal de la historia de la humanidad. Son precisamente esas disciplinas que, habiéndose individualizado en el siglo XIX, llevaron a la reducción gradual de los períodos históricos estudiados las que hoy permiten una mejor comprensión 
unificada del pasado «profundo». El impulso, sin embargo, debe continuar viniendo del mundo de la universidad, que siempre ha sido responsable de la formación de nuevos intelectuales, destinados al desarrollo de nuevas visiones y planes para el mundo futuro gracias a la comprensión del pasado.

\section{Bibliografia}

Armitage, D. \& Guldi, J. (2014). History Manifesto. Cambridge: Cambridge University Press.

Aullón de Haro, P. (2016). La Escuela Universalista Española. Madrid: Sequitur.

Ben-Tov, A. (2009). Luteran Humanists and Greek Antiquity. Melanchthonian Scholarship Between Universal History and Pedagogy. Leiden-Boston: brill.

Bussac, E. \& Germain, Y. (coords.). (2010). Chronique du règne de Saint Louis (12261270) de Guillaume de Nangis. Paris : Editions Paleo.

Calhoun, C. (2008). Social Science for Public Knowledge. En S. Eliaeson, R. Kalleberg (Eds.), Academics as Public Intellectuals. Newcastle upon Tyne: Cambridge Scholars Publishing.

Feltri, S. (2016). Università, ora è ufficiale: alcune lauree sono inutili. Il Fatto Quotidiano. 26/09/2016.

Foucault, M. (1975). Surveiller et punir. Naissance de la prison. Paris : Gallimard.

Habermas, J. (1977). Storia e critica dell'opinione pubblica. Roma-Bari: Laterza.

Harari, Y. N. (2018). 21 Lessons for the 21st Century. London: Jonathan Cape.

Harari, Y. N. (2016). Homo Deus: A Brief History of Tomorrow. London: Harvill Secker.

Harari, Y. N. (2014). Sapiens: A Brief History of Humankind. London: Harvill Secker.

Hartog, F. (2013). Croire en l'histoire. Paris, Flammarion.

Hérvas, Y. \& Panduro, L. (1778-1787). Idea dell'universo che contiene la storia della dell'uomo, elementi cosmografici, viaggio estatico al mondo planetario e storia della terra. 21 voll., Cesena: per Gregorio Blasini.

Hobsbawm, E. (1994). The Age of Extremes: The Short Twentieth Century: 1914-1991. New York: Vintage Books.

Hourmouziadis G. (Ed.). (2002). Dispilio 7500 hronia meta. Thessaloniki: Thessaloniki University Press.

Koselleck, R. (1975). Geschichte, Historie. Stuttgart: Klett.

Le Goff, J. \& Nora, P. (Coords.). (1974). Faire de l'histoire. 3 voll. Paris: Gallimard.

Le Goff, J. (2014). Faut-il vraiment découper l'histoire en tranches ? Paris: Editions du Seuil. 
Le Goff, J. (1988). Histoire et mémoire. Paris: Gallimard.

Lord Smail, D. (2008). On Deep History and the Brain. Oakland: University of California Press.

Lord Smail, D., Shryock, A. (2011). Deep History. The Architecture of Past and Present. Berkeley: University of California Press.

McCoy, F. (1974). Researching and Writing in History: A Practical Handbook for Students. Berkeley: University of California Press.

Mortley, R. (1990). The Hellenistic Foundations of Ecclesiastical Historiography. En G. Clarke (Ed.). Reading the Past in Late Antiquity. Rushcutters Bay: Australian National University Press.

Mortley, R. (1996). The Idea of Universal History from Hellenistic Philosophy to Early Christian Historiography. Lewiston: Mellen Press.

Rodgers, D. (2011). Age of Factures. Cambridge (MA): Belknap.

Roediger, D. (1991). Wages of Whiteness: Race and the Making of American Working Class. London-New York: Verso.

Romio, R. (Ed.). (2018). Didattica per un nuovo umanesimo. Linguaggi e metodologie della didattica ermeneutica esistenziale. Torino: Elledici.

Rossi, P. (1984). The Dark Abyss of Time: The History of the Earth and the History of Nations from Hooke to Vico. Chicago: The University of Chicago Press.

Scott, J. (2017). Against the Grain: A Deep History of the Earliest State. New Haven: Yale University Press.

Sisci, F. (2013). An alternative route for China’s ascent. Asia Times, 23/04/2013.

Suggi, A. (1998). Cronologia e storia universale nella Methodus di Jean Bodin. I castelli di Yale. III.

Van Nuffelen, P. (2010). Theology versus Genre? The Universalism of Christian Historiography in Late Antiquity. En A. Fear \& P. Liddel (Coords.). Historiae Mundi. Studies in Universal History. London-New York: Bloomsbury.

Vico, G. (1744). Principj di scienza nuova d'intorno alla comune natura delle nazioni. Napoli: Stamperia Muziana.

Voltaire. (2014). Il secolo di Luigi XIV. Torino: Einaudi. 